\title{
APPLYING SATELLITE TECHNOLOGY TO ENERGY AND MINERAL EXPLORATION
}

by

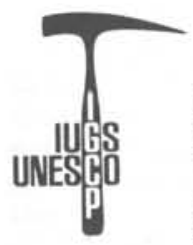

IGCP Project 143 ("Remote Sensing and Mineral Exploration"), is a worldwide research project designed to make satellite data an operational geological tool along with the geologic pick, hand lens, topographic map, aerial photo and geophysical instruments and data that comprise the exploration package. While remote sensing data will not replace field exploration and mapping, careful study of such data prior to field work should make the effort more efficient.

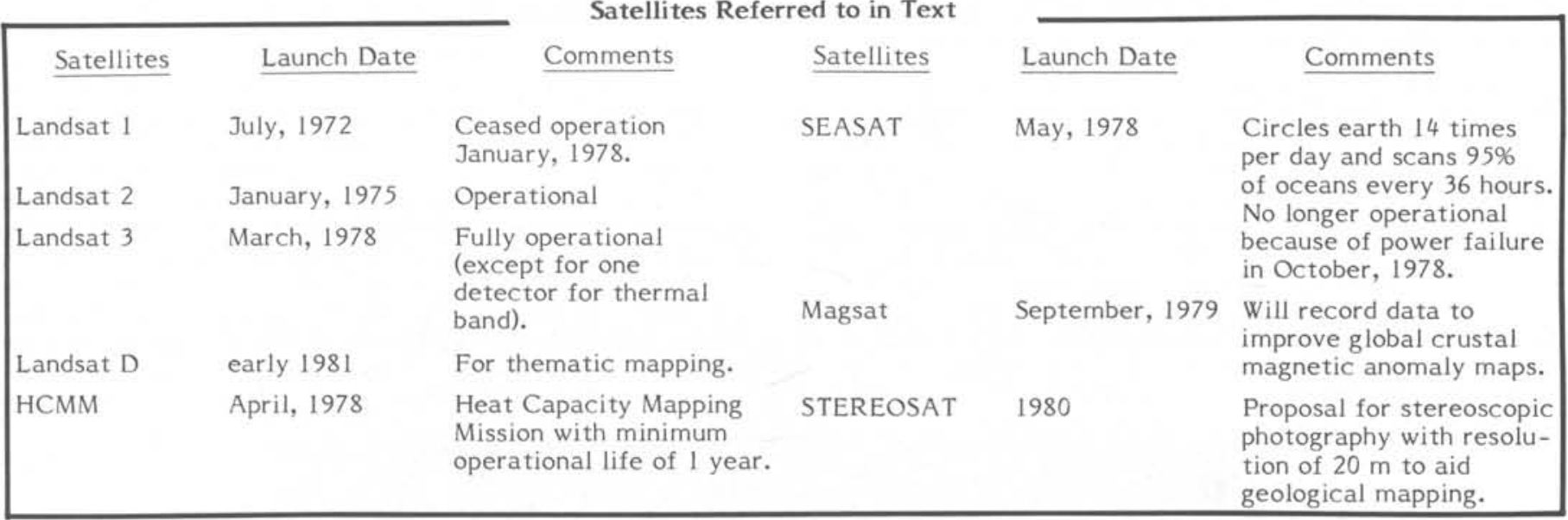

Images acquired by Landsat 1, 2 and 3 are being studied by a worldwide group of 150 geologists in 45 countries under IGCP Project 143, "Remote Sensing and Mineral Exploration," using visual and computer analysis techniques to develop new methods for mineral exploration. The synoptic view of large areas and repetitive nature of Landsat data collection have enabled the investigators to obtain data at variable sun angles and seasons in both the northern and southern hemispheres and the digital format of the data greatly facilitates computer processing of the images. Visual analyses have concentrated on delineation of lineaments and geomorphic units such as bedrock vs. alluvial domains, and drainage

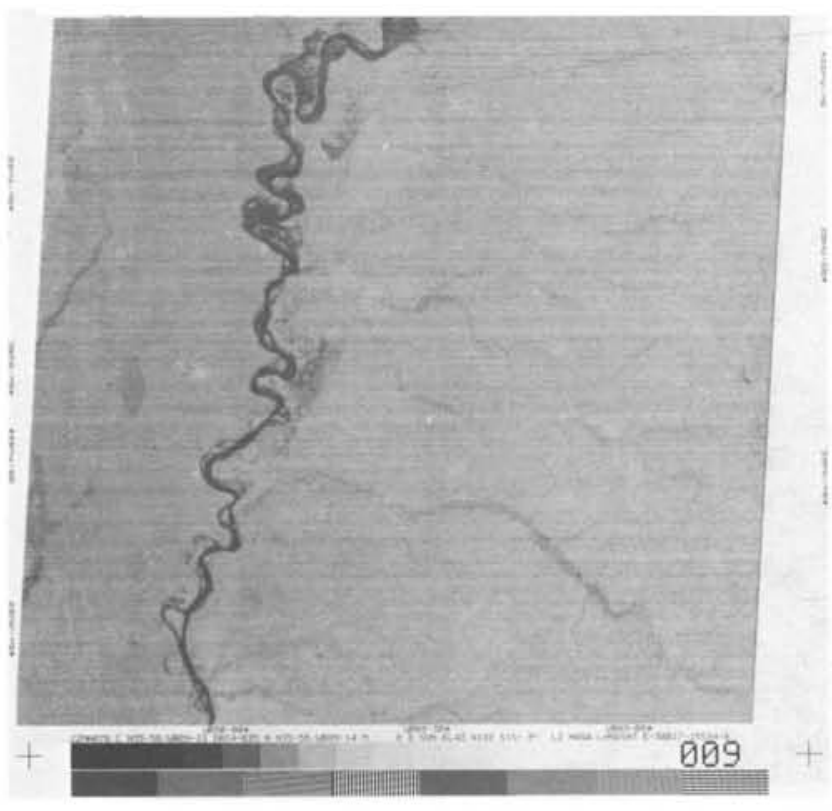

A

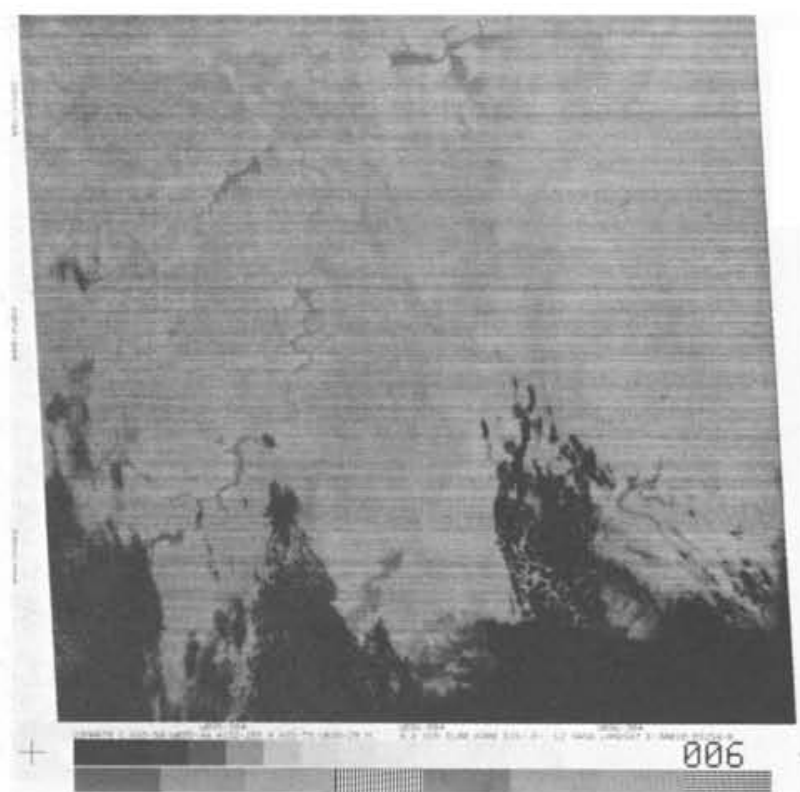

B

Figure 1. An example of Landsat 3, band $8(10-12.5 \mu \mathrm{m})$ thermal imagery taken on $a$ daytime pass over the United States (A) as compared with a night-time image over another area of the Central United States (B). 


\section{patterns.}

Computer processing techniques provide methods of edge enhancement to improve definition of drainage and fracture patterns. Ratioing of the Landsat spectral bands has been used for identifying and mapping the extent of hematitic hydrothermal alteration zones that may be related to ore deposits. Supervised parallelepiped computer analysis has been used to measure the reflectance of exposed rock surfaces and correlate exposures across international boundaries. Unsupervised maximum likelihood programs have been successfully used to classify surface terrain classes of various kinds. Computer programs have also been developed to combine Landsat data with other types of information. The most exciting of these was recently accomplished by Green, Huntington, and Roberts (1978) in Australia where Landsat data and digitized magnetic data were merged to provide a three-dimensional stereoscopic display in which magnetic trends are clearly portrayed as highs and lows. The close relationship of visible lineaments on Landsat data with magnetic trends in this area was clearly demonstrated.

Although the Landsat 3 thermal band (Band 8, $10-12.5 \mu \mathrm{m})$ failed a few months after its launch in 1978, there may be sufficient data collected to make limited preliminary evaluations of the system (Fig. 1). Initial images of the Heat Capacity Mapping Mission (HCMM) were recently made available and look very promising as a tool to measure emitted thermal radiation from the Earth surface (Fig. 2). The first synthetic aperture data radar (SAR) from SEASAT-1 indicates many valuable uses which include mapping sea-wave patterns, sea ice distribution and dynamics as well as earth terrain features. The possibility of combining improved geomorphic information from the SAR data with Landsat spectral radiance and thermal emittence data to enhance interpretation methods is attractive.

The potential of remote sensing data, especially in poorly mapped or unmapped regions of the world, is readily recognized by the GEOSAT Committee of the U.S.A. and the INDUSAT Group of Australia, two confederations of mineral and petroleum companies and consultants that have formed to review industry information requirements and present these to interested government agencies. The activity of these committee groups clearly demonstrates industry interest in the space program. Recommendations by the GEOSAT Committee were instrumental in the selection of the $2.2 \mu \mathrm{m}$ band, which is of value in differentiating rock types for Landsat D and has started initial studies for the panchromatic STEREOSAT data collection system to be compatible with Landsat data. In Australia, INDUSAT support influenced the decision to build a Landsat receiving station that will come on line in 1979.

\section{Growth of receiving stations}

The growing number of receiving stations around the world is another measure of the value of Landsat data to the world renewable and non-renewable resource picture. In 1972, there were three previously established NASA stations at Greenbelt, Maryland, Goldstone, California, and Fairbanks, Alaska, to support early meteorological and manned flight experiments which were used to receive Landsat images. Canada was the first country to build a Landsat station at Prince Albert in Saskatchewan (1972) and later at Shoe Cove (1978). Brazil followed by constructing a station at Cuiaba in 1974, Italy built one at Fucino (1977), and a station is now operating in Iran (1978). Under construction are stations in Argentina, Australia, Japan, Sweden, India, and Upper Volta;

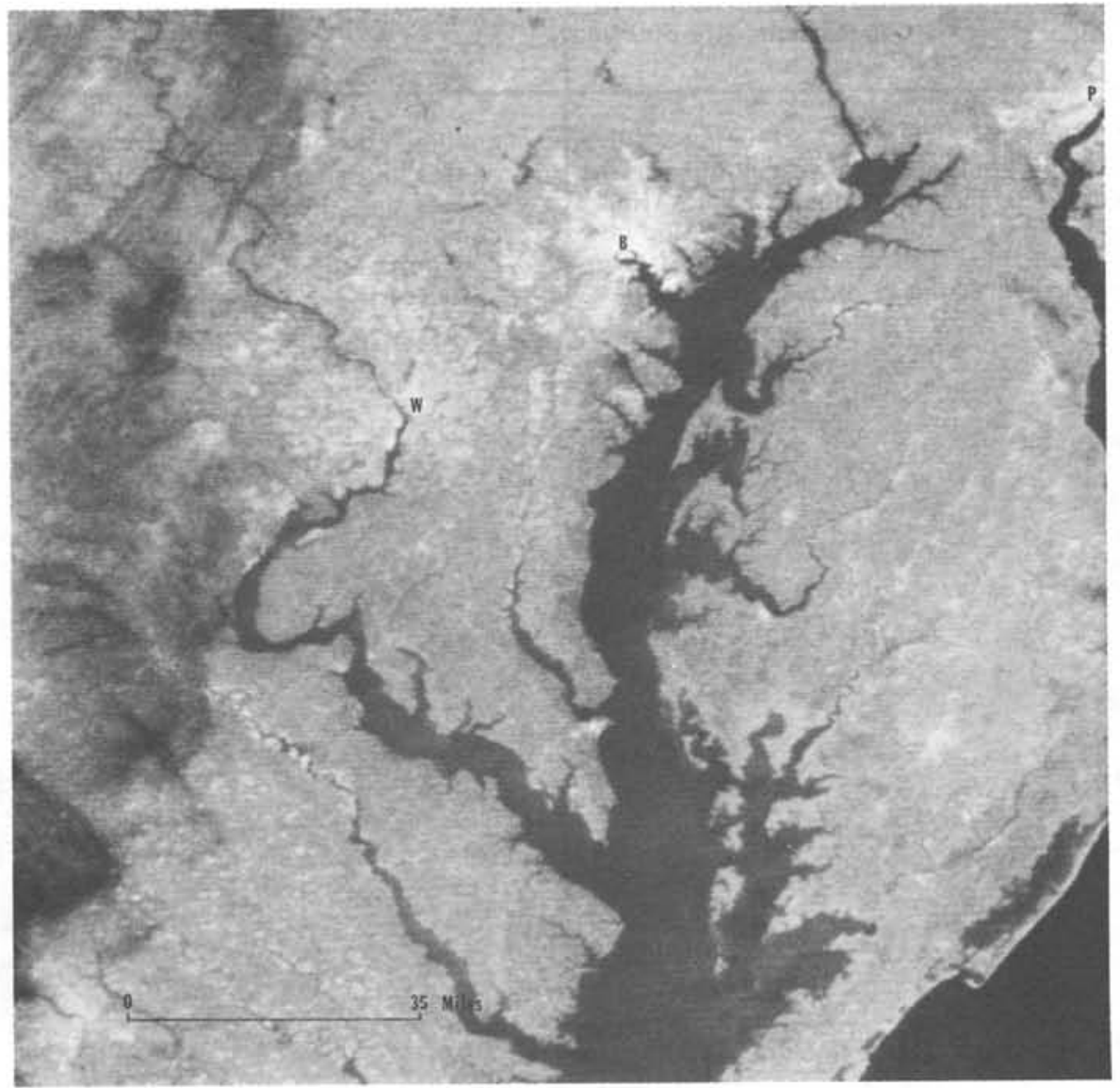

Figure 2. Part of the first daytime thermal $(10.5-12.5 \mu \mathrm{m})$ infrared image of the Chesapeake Bay area, Atlantic Coast Region of the United States acquired by NASA's Heat Capacity Mapping Mission (HCMM) on Applications Explorer Mission-1 (AEM-1) on May 11, 1978, from an altitude of $620 \mathrm{~km}$. Gray levels indicate relative temperatures from black (cold) to white (hot). Washington, D.C. (W), Baltimore, Md. (B), and part of Philadelphia (P) stand out as bright (hot) features due to the urban heat island effect. (Photo courtesy NASA) 
a number of other stations are in various stages of negotiation and design. It is quite likely that most of the major land areas of the world, except Antarctica, will be covered by 1981.

Project 143 research efforts are currently aimed mainly at field verification of features identified by visual or computer assisted interpretation of Landsat data. Major research efforts are aimed at defining alteration zones relating to ore deposits in desert areas and anomalous vegetation patterns in forested areas, particularly in the jungle regions of the world where exploration is difficult. Other data from sources such as SEASAT, HCMM, and Magsat will be similarly evaluated. New terminology related to these new data have been defined and clarified by O'Leary and others (1976); symbology that distinguish satellite-derived geologic features from field-mapped features have been designed (O'Leary and Friedman, 1978) and if accepted on a global basis, will be recommended to the Commission for the Geological Map of the World.

Construction of national Landsat mosaics has been encouraged to provide a pictorial overview that can be compared with national resource maps. Mosaics currently exist for the U.S., Canada, Mexico, Bolivia, Brazil and Argentina in the western hemisphere and are available at various scales. Mosaics of France, Spain, and the British Isles have also been brought to the attention of the authors. The U.S. and Alaska were combined with mosaics of Mexico and Canada in preliminary form at a scale of $1: 10000000$. In spite of the fact that they were each compiled on slightly different map projections and the junction between the segments is not precise, the composite mosaic provides an overview that permits a new appreciation of the various tectonic provinces of the continent (Fig. 3). A lineament

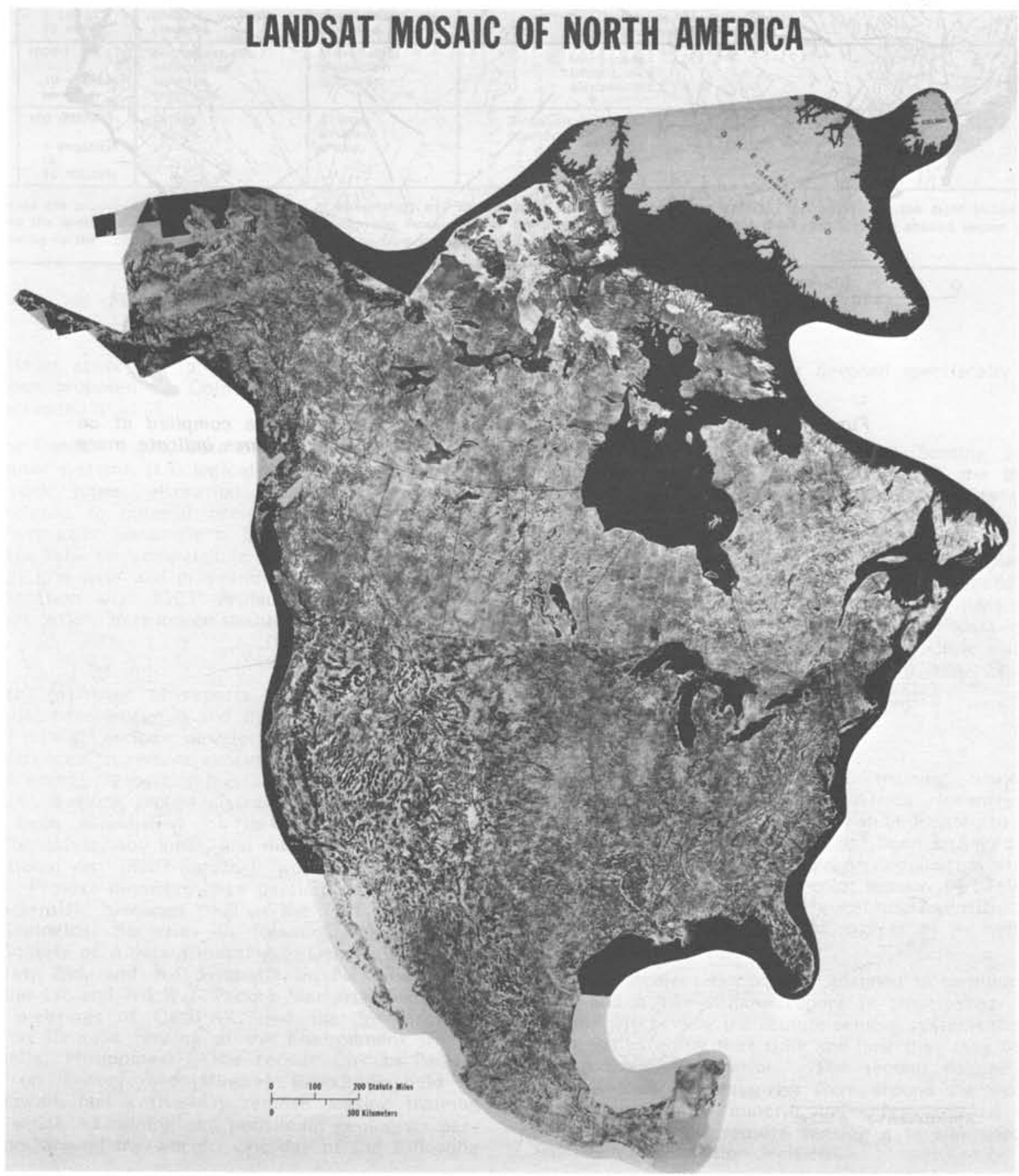

Figure 3. Landsat mosaic of North America made by combining mosaics of Alaska and the conterminous United States with those of Canada (courtesy Canada Centre for Remote Sensing) and Mexico (courtesy Consejo de Recursos Minerales). Original scale 1:10 000000 . 
analysis clearly demonstrates the filtering effect provided by extremely small scale analysis versus the results obtained from larger scale products, as shown in Figures 4 and 5 . A logical classification system for lineaments, faults and

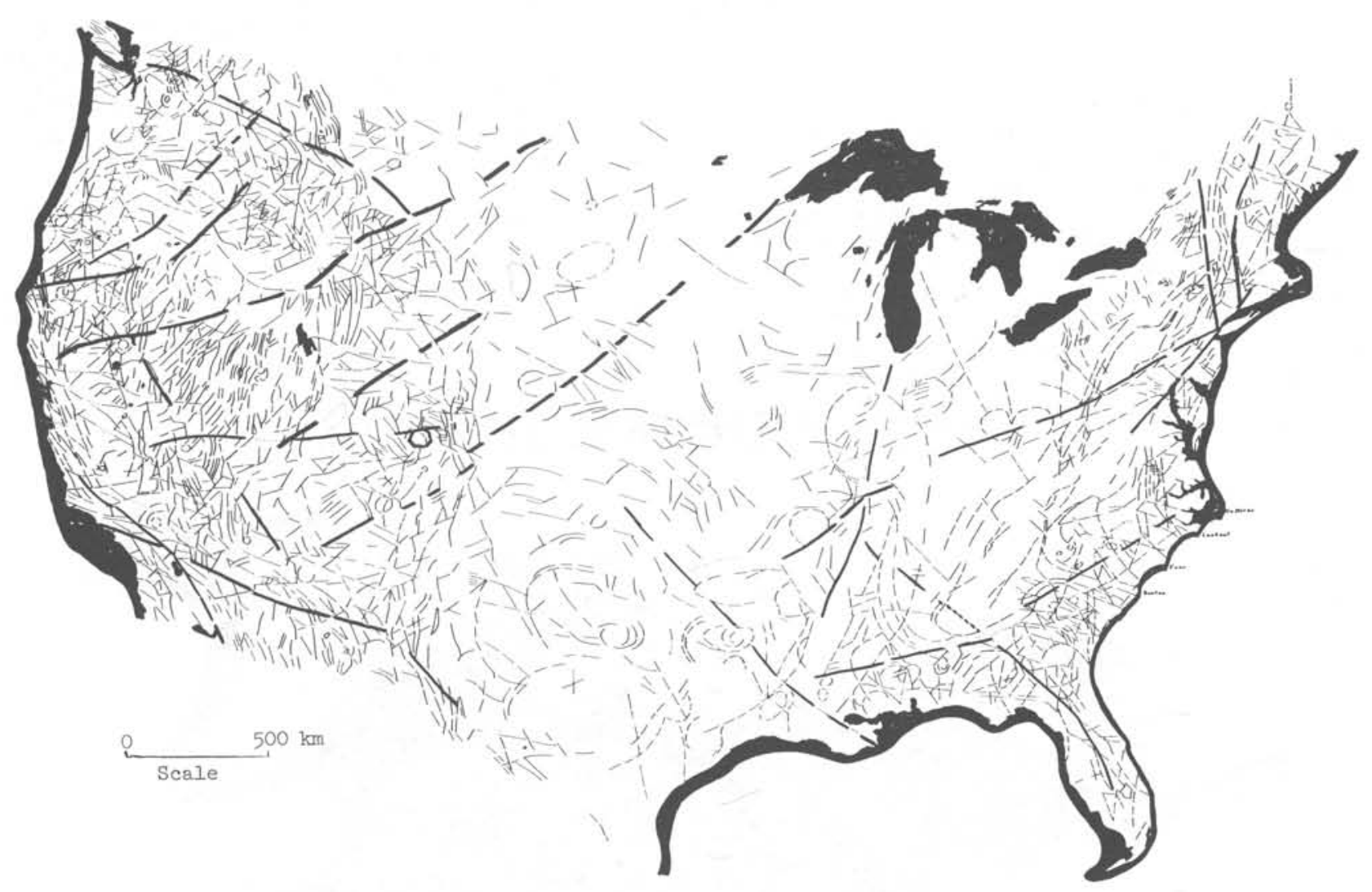

Figure 4. Lineament map of the conterminous United States compiled at an original scale of 1:5000 000 by W.D. Carter (1974). Heavy lines indicate more significant features.

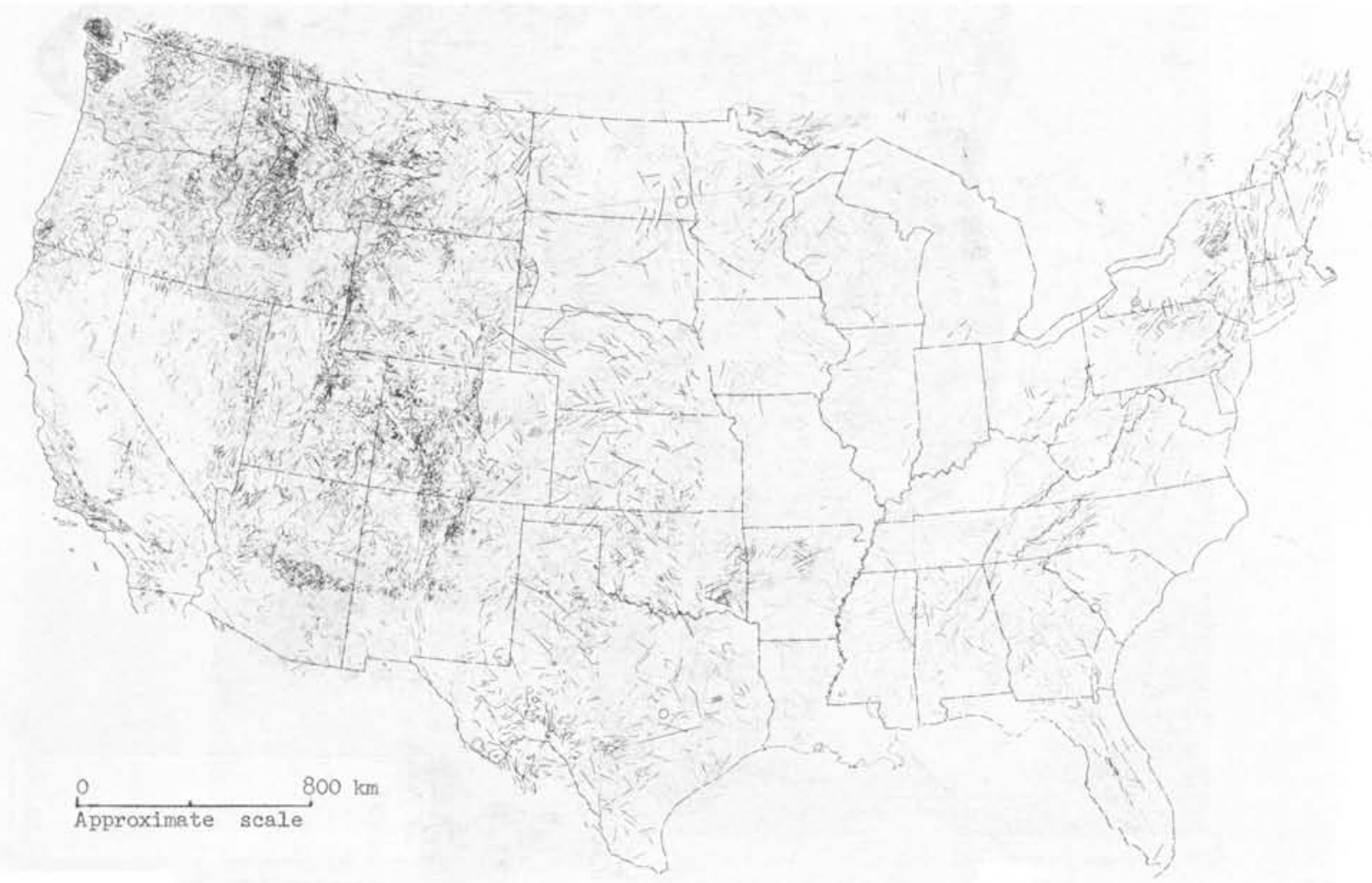

Figure 5. Lineament map of the conterminous United States compiled at an original scale of 1:1 000000 by W.D. Carter, B. Lucchitta, and G. Schaber in 1976. Solid lines indicate features identified by three interpreters, dashed lines were identified by two interpreters and dotted lines indicate features identified by one interpreter. 
TABLE 1. OPTIMUM SCALES AND CORAESPONDING SENSING PLATFORMS FOR MAPPING DEFORMATION AND GEOTECTONIC PHENOMENA

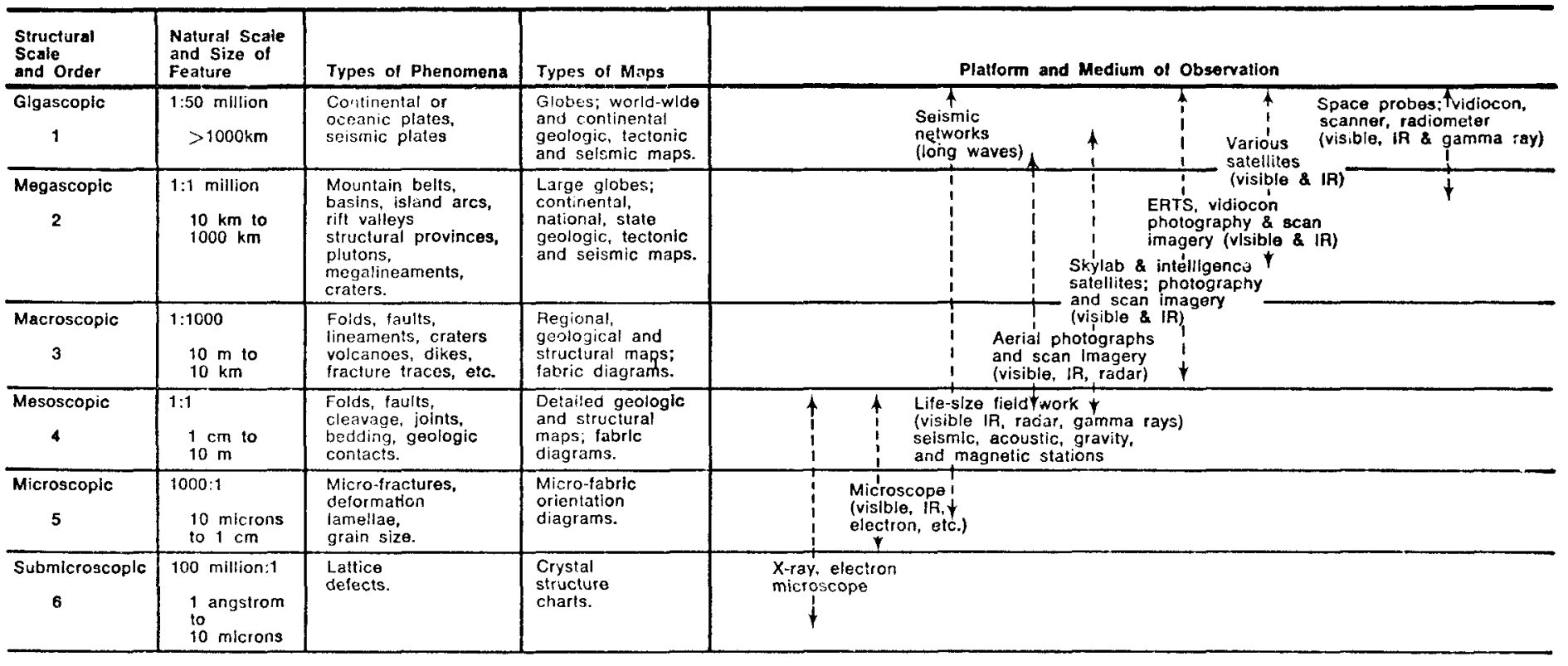

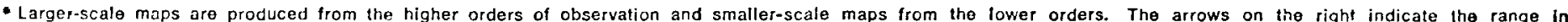

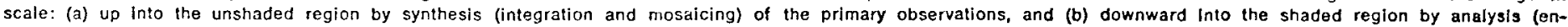
larging and enhancng to the limit of resolution). Compiled from various sources (Ref. $3,4,5$ ).

Figure 6. Metric Classification of Lineaments proposed by D.P. Gold et al. (1974).

fracture systems according to scale and length in metric units has been proposed by Gold (1974) and is becoming universally accepted (Fig. 6).

Because Landsat digital data can be analyzed by interactive computer systems, it is logical that spectral measurements of rock types, alteration zones and vegetation anomalies related to mineral occurrences, together with pertinent observation parameters, be entered into a computerized data bank for comparative reference. The details of formatting the data and programming are being worked out in cooperation with IGCP Project 98 "Standards for computer applications in resource studies."

\section{Publications}

A lively exchange of reports on research in IGCP Project 143 has been initiated and this and other activities are reported through periodic newsletters. A bibliography of over 500 references on remote sensing, plate tectonics, and mineral and energy resources has been distributed to all participants. * Working groups distributed on a geographic basis have been established in North America, Europe, Australia, Yugoslavia, and India, and meet once or twice a year. National or multi-national working groups are encouraged. Project members have participated in a wide variety of scientific meetings such as the 1976 meeting of European Geological Societies in Reading, England, the Geological Society of America meeting in Denver, Colorado, 1977, the 1st, 2nd, and 3rd Symposia on New Basement Tectonics, the 1st and 3rd W.T. Pecora Memorial Symposia, the annual meetings of COSPAR, and the International Symposium on Remote Sensing of the Environment (April, 1978 in Manila, Philippines). The recent Circum-Pacific Conference on Energy and Mineral Resources held in Honolulu, Hawail, had a five-day remote sensing training program in which 43 mining and petroleum geologists participated from around the worid. One day of the following week-long conference was devoted specifically to remote sensing.

A special session on Remote Sensing and Mineral Exploration was held in conjunction with the International Association on the Genesis of Ore Deposits (IAGOD) in August, 1978, at Alta, Utah. Participants from Australia, South America, Europe, and Asia Minor attended. A special one-day session on remote sensing took place at the Geological Society of America meeting in Canada in October 1978 and project members took an active part in that. A paper reporting on the application of Landsat data to the problems of the small mine operator in Chile was presented at a UN Conference on "The Future of Small Scale Mining", Mexico City, Mexico, in November, 1978.

\section{Future Plans}

Plans for 1979 include training workshops and conferences in Bolivia and Africa (country not yet determined) if adequate funding can be located to support the activity. A two-day workshop has been arranged for June 5 and 6, 1979 in Bangalore, India, in conjunction with the 22nd Meeting of COSPAR. A special session in "Teledetection" has been planned for the technical and scientific program of the International Geological Congress to be held in Paris, France in 1980.

The project is currently planned to terminate in about 1981 and a two-volume report is anticipated. The first volume will review the remote sensing systems that will have been evaluated by that time and how they may be employed for geologic exploration. The second volume will be a collection of case histories from around the world dealing with a variety of mineral and energy-related exploration problems and how remote sensing data was used and contributed to exploration decisions.

* It may be obtained by writing to the authors of this articte at the U.S. Geological Survey in Reston, Virginia, U.S.A. 
Gold, D.P., Alexander, S.S., and Parizek, R.R., 1974, Application of Remote Sensing to Natural Resource and Environment Problems in Pennsylvania: Earth and Mineral Sciences Bull., Penn. State Univ., v. 43, no. 7, p. 49-53.

Green, A.A., Huntington, J.F., and Roberts, G.P., 1978, Landsat Digital Enhancement Techniques for Mineral Exploration in Australia: Proc. 12th Int. Symp. on Remote Sensing of the Environment, Manila, Philippines, 8 p. (in press).

O'Leary, D.W., Friedman, J.D., and Pohn, H.A., 1976, Lineaments, Linear and Lineation - Some Proposed New Standards for Old Terms: Bull. Geol. Soc. of America, v. 87, p. 1463-1469.

O'Leary, D.W. and Friedman, J.D., 1978, Towards a Workable Lineament Symbology: 3rd Int. Con. on Basement Tectonics, Durango, Colo., May 1978 (Prog. Abs.), p. 37.

\section{ABOUT THE AUTHORS:}

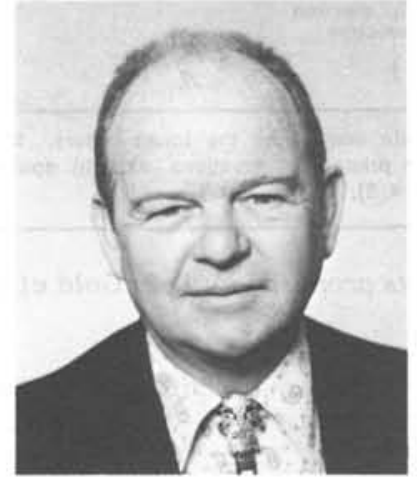

William D. Carter, co-leader of IGCP Project 143 and IUGS' representative to ICSU's Committee on Space Research, is a mineral resource geologist who has worked with the U.S. Geological Survey since 1948. A graduate of Dartmouth and Johns Hopkins Universities, Dr. Carter has served in Chile under USAID and in Washington, D.C. as Silica Commodity Geologist in the Branch of Light Metals and Industrial Minerals. He has been involved in remote sensing since 1965 - as coordinator for the Geological Division, USGS, as Assistant Program Manager for Applications Research, EROS Program, and as research scientist. He serves also as part-time consultant to the Inter-American Development Bank.

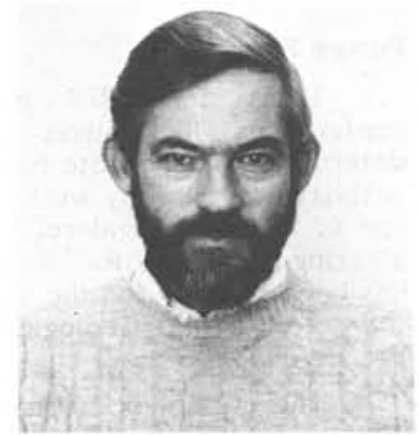

Lawrence C. Rowan, a graduate of the universities of Virginia and Cincinnatti, is currently coordinator of remote sensing activities in the U.S. Geological Surveys' nuclear waste storage and mineral resource programs and co-investigator of a spectral reflectance experiment to be conducted on the second Space Shuttle mission. Dr. Rowan has been studying the relationship between mineral content and spectral reflectance for developing additional techniques for remote lithologic mapping, and was the principal investigator for an ERTS-1 experiment which developed the colour-ratio compositing technique for detecting and mapping limonitic alteration zones in MSS images.
Send for a free brochure...
AAPG Studies in Geology No. 6

\section{Contributions to \\ The Geologic Time Scale}

\author{
edited by \\ George V. Cohee, Martin F. Glaessner, \\ and Hollis D. Hedberg
}

Now you can have the most complete, up-to-date, collection of papers on time scales and stratigraphic correlation - all between two covers for quick reference.

The volume ( 388 pages) offers the reader an aid to continental and global correlation. Topics cover every time period, and are based on papers presented at Time Scale Symposium 106.6, at the 25th International Geological Congress (Sydney 1976).

You need this book for your reference shelf. Printed August 1978 (paperback), the volume is possibly the most significant collection of information since Harland's 1964 Phanerozoic Time Scale.

\section{AAPG Catalog No. 805.}

\section{Price: $\$ 19$ ( $\$ 16$ to AAPG-SEPM members)}

Order now from AAPG Publications, or write today for a free descriptive brochure or catalog:
AAPG Publications
Room 224
P.O. Box 979
Tulsa, Oklahoma 74101
U.S.A. 